\title{
Evaluation of brightness temperature from a forward model of ground-based microwave radiometer
}

\author{
S Rambabu ${ }^{1, *}$, J S Pillai ${ }^{1}$, A Agarwal ${ }^{1}$ and G Pandithurai ${ }^{2}$ \\ ${ }^{1}$ Society for Applied Microwave Electronics Engineering and Research (SAMEER), \\ Indian Institute of Technology, Bombay, Mumbai 400 076, India. \\ ${ }^{2}$ Indian Institute of Tropical Meteorology (IITM), Pune 411 008, India. \\ ${ }^{*}$ Corresponding author.e-mail: rametsiri@gmail.com
}

Ground-based microwave radiometers are getting great attention in recent years due to their capability to profile the temperature and humidity at high temporal and vertical resolution in the lower troposphere. The process of retrieving these parameters from the measurements of radiometric brightness temperature $\left(T_{B}\right)$ includes the inversion algorithm, which uses the background information from a forward model. In the present study, an algorithm development and evaluation of this forward model for a ground-based microwave radiometer, being developed by Society for Applied Microwave Electronics Engineering and Research (SAMEER) of India, is presented. Initially, the analysis of absorption coefficient and weighting function at different frequencies was made to select the channels. Further the range of variation of $T_{B}$ for these selected channels for the year 2011, over the two stations Mumbai and Delhi is discussed. Finally the comparison between forward-model simulated $T_{B} \mathrm{~S}$ and radiometer measured $T_{B} \mathrm{~S}$ at Mahabaleshwar $\left(73.66^{\circ} \mathrm{E}\right.$ and $\left.17.93^{\circ} \mathrm{N}\right)$ is done to evaluate the model. There is good agreement between model simulations and radiometer observations, which suggests that these forward model simulations can be used as background for inversion models for retrieving the temperature and humidity profiles.

\section{Introduction}

Profiling of the atmosphere through the network of in situ radiosonde (RS) observations and remotesensing (satellites) observations is of great importance to represent the initial three-dimensional structure of the atmosphere in numerical weather prediction models. But these two approaches have their own limitations in their measurements of temperature and humidity. The radiosonde gives the in situ measurements along the path followed by the drifting balloon, but not exactly at a vertical point of the releasing station. In addition, their costly unrecoverable operation limits the spatial and temporal coverage. The above limitations of the radiosonde are overcome by satellite remote sensing technique measurements by providing the observations vertically over a station with good spatial and temporal resolution. These satellite observations are quite important in the numerical models especially over data sparse oceanic regions. However, the vertical resolution of satellite measurements is good in higher altitudes and sparse near surface levels where major exchanges of momentum, heat and moisture fluxes take place. This problem can be overcome by the same remote sensing technique from ground-based instruments by which high vertical resolution measurements at surface levels are possible. Usefulness of ground-based microwave radiometry for retrieving the profiles of temperature and humidity has been proven quite some time ago (Westwater 1965;

Keywords. Microwave radiometer; brightness temperature; inversion model; forward model. 
Decker et al. 1978; Askne and Westwater 1986). In the last few years, technical improvements and the intensifying search for alternatives to radiosonde has led to the development of multichannel microwave radiometers for the operational profiling of tropospheric temperature and humidity (Del Frate and Schiavon 1998; Solheim et al. 1998). With the advantages of continuous profiling in time and good vertical resolution close to the ground in the planetary boundary layer, this technique may get importance by providing high resolution data to assimilate into the numerical weather prediction models. A good network of operational radiometers along with radiosonde and satellite measurements may definitely meet the requirement of high resolution models in the near future.

Retrieval of profiles of temperature and humidity from a radiometer includes the conversion of its measured radiances (brightness temperature) into atmospheric parameter through inversion model as depicted in figure 1. This can be achieved by comparing simulated radiances (prior information) from the forward model, which calculates the brightness temperature from the known atmospheric parameters as depicted in figure 2. The simulation of brightness temperature in forward model is mainly dependent on weighting functions for different weather parameters, which in-turn, are dependent on atmospheric absorption of that channel frequency. In the present article, the process of algorithm development for a forward model and evaluation of brightness temperatures simulated by

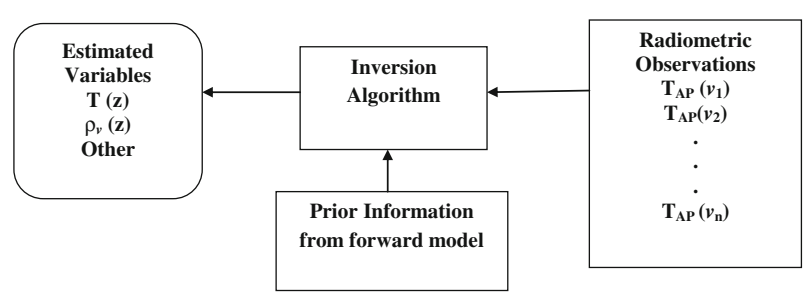

Figure 1. Elements of inverse model for an upward-looking microwave radiometer.

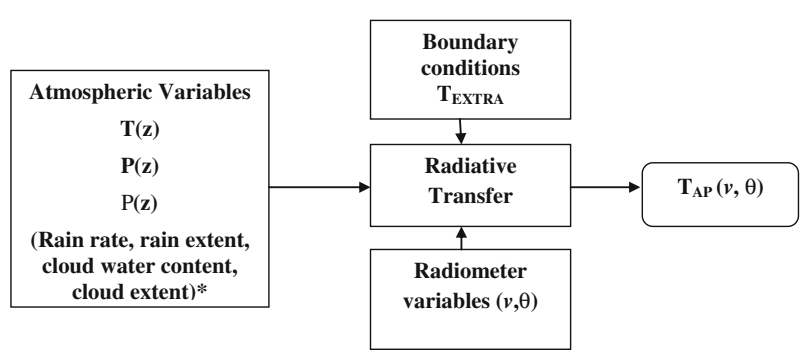

Figure 2. Elements of forward model for an upward-looking microwave radiometer. this forward model with a ground-based microwave radiometer measurements are presented.

\section{Radiative transfer equation}

In the forward model, as shown in figure 2, the major component is radiative transfer model (RTM) which estimates $T_{B} \mathrm{~s}$ in different frequency channels from the known atmospheric state (temperature, pressure and humidity). This RTM generally uses a radiative transfer equation of the form (Ulaby et al. 1981):

$$
T_{\mathrm{AP}}(v, \theta)=T_{\mathrm{DN}}(v, \theta)+T_{\text {extra }}(v) e^{-\tau_{v} \sec \theta} .
$$

In the above equation, second term of the right hand side is the down-welling cosmic contribution $(\sim 2.7 \mathrm{~K})$ and first term of the right hand side represents the atmospheric contribution of down-welling radiation and is given by:

$$
T_{\mathrm{DN}}(v)=\int_{0}^{\infty} W(v, z) T(z) d z
$$

where ' $v$ ' is the channel frequency, $\theta$ is the zenith angle at which radiometer is looking. $W(v, z)=$ $\alpha_{v}(z) e^{-\tau_{v}(0, z)}$ and $\tau_{v}(0, z)=\int_{0}^{z} \alpha_{v}(z) d z$ are called weighting function and zenith optical thickness of the atmospheric layer. ' $T(z)$ ' is the temperature of the atmospheric layer $z$. The schematic diagram of these contributions is shown in figure 3 . Hence from the vertical profiles of atmospheric variables like pressure, temperature, and humidity of different layers, absorption coefficient $\left(\alpha_{v}\right)$, weighting function and then the apparent brightness temperature can be simulated.

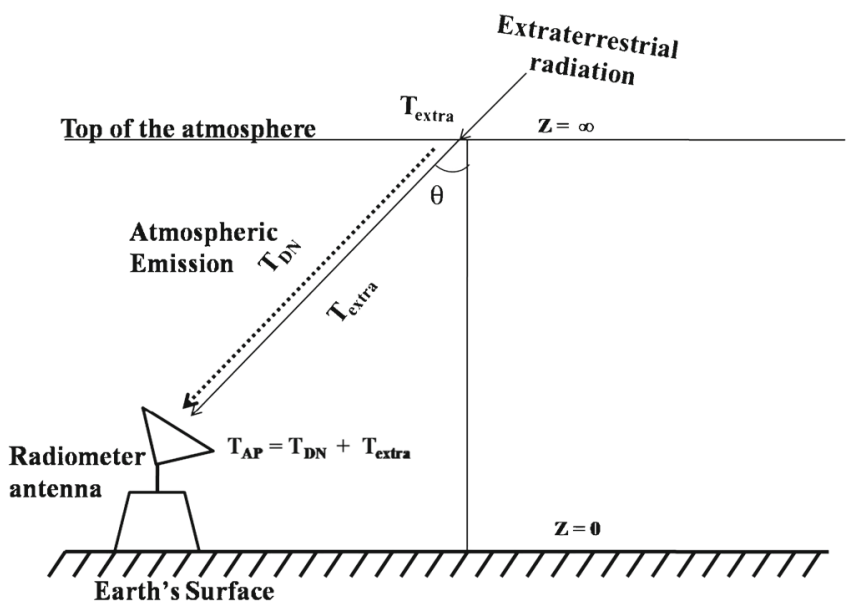

Figure 3. Components contributing to an upward-looking radiometer at a zenith angle $\theta$. 


\section{Atmospheric absorption model and data used}

Radiation is absorbed when a transition takes place from a lower energy state to a higher energy state. The transition may involve changes of electronic, vibrational, or rotational energy or any of the three types. The absorption spectrum due to single transition is called a transition line. Out of the various gases of the atmosphere, the main natural absorbers are oxygen and water vapour. The oxygen molecule has a permanent magnetic moment. Magnetic interaction with the incident field produces a family of rotation lines in the vicinity of $60 \mathrm{GHz}$ and an isolated line at $118.8 \mathrm{GHz}$. Water vapour on the other hand, is a polar molecule with an electric dipole. Electric interaction with the incident field produces rotation lines at $22.2,183.3 \mathrm{GHz}$ and several frequencies in the far-infrared region. For the past few years, the propagation characteristics of the atmosphere have been modelled by many people, like Ulaby et al. (1981), Millimeter wave Propagation Model (MPM) of Liebe et al. (1993), Liebe (1987, 1989), etc. However, with the advantage of including more components like liquid water and ice particles contribution in the propagation, better results are derived in precise simulations. MPM model has been widely used around the world for the propagation measurements. The details of the MPM (Liebe et al. 1993) propagation model which is used in the study for atmospheric absorption coefficient measurements are described below.

\subsection{MPM model (Liebe1993)}

In the atmospheric MPM model, modular, quantitative relationships were developed between meteorological conditions encountered in the neutral atmosphere and corresponding refractivity. According to Liebe93 model, the spectral characteristics of the atmospheric medium are expressed by a complex refractivity,

$$
\begin{aligned}
\mathrm{N} & =\mathrm{N}_{\mathrm{D}}+\mathrm{N}_{\mathrm{V}}+\mathrm{N}_{\mathrm{W}} \\
& =\mathrm{N}_{0}+\mathrm{N}^{\prime}+\mathrm{iN}^{\prime \prime} \mathrm{ppm}
\end{aligned}
$$

where $\mathrm{N}_{\mathrm{D}}, \mathrm{N}_{\mathrm{V}}$ and $\mathrm{N}_{\mathrm{W}}$ are refractivity due to dry air, water vapour, and cloud module, respectively. The real part of the $\mathrm{N}$ that is $\left(\mathrm{N}_{0}+\mathrm{N}^{\prime}\right)$ changes the propagation velocity and consists of a frequency-independent term $\left(\mathrm{N}_{0}\right)$, plus the dispersive refraction $\left(\mathrm{N}^{\prime}\right)$. The imaginary part $\left(\mathrm{iN}^{\prime \prime}\right)$ quantifies the loss of radiation energy (absorption). From refractivity, power attenuation can be obtained by:

$$
\alpha=0.1820 v \mathrm{~N}^{\prime \prime} \mathrm{dB} / \mathrm{km} .
$$

In refractivity calculation, the model considers 44 Oxygen $\left(\mathrm{O}_{2}\right)$ and 34 water vapour $\left(\mathrm{H}_{2} \mathrm{O}\right)$ local lines (centered below $1000 \mathrm{GHz}$ ).

Refractivity of dry air (dry air module) is expressed by:

$$
\mathrm{N}_{\mathrm{D}}=\mathrm{N}_{\mathrm{d}}+\sum_{\mathrm{k}} \mathrm{S}_{\mathrm{k}} \mathrm{F}_{\mathrm{k}}+\mathrm{N}_{\mathrm{n}}
$$

Here, $\mathrm{N}_{\mathrm{d}}$ is nondispersive term; $\sum_{\mathrm{k}} \mathrm{S}_{\mathrm{k}} \mathrm{F}_{\mathrm{k}}$ is contribution from 44 oxygen line terms; $\mathrm{N}_{\mathrm{n}}$ is nonresonant terms' contribution, which includes nonresonant $\mathrm{O}_{2}$ spectrum and pressure induced $\mathrm{N}_{2}$ absorption.

Refractivity of water vapour (water vapour module) is written in the form

$$
\mathrm{N}_{\mathrm{V}}=\mathrm{N}_{\mathrm{v}}+\sum_{\mathrm{l}} \mathrm{S}_{\mathrm{l}} \mathrm{F}_{1}+\mathrm{N}_{\mathrm{c}}
$$

Here, $\mathrm{N}_{\mathrm{v}}$ is non-dispersive term; $\sum_{1} \mathrm{~S}_{1} \mathrm{~F}_{1}$ is contribution from $34 \mathrm{H}_{2} \mathrm{O}$ line terms; $\mathrm{N}_{\mathrm{c}}$ is continuum spectrum.

The interaction of suspended water droplets and ice crystals (fog/cloud module) with radio waves is treated by employing the Rayleigh approximation for Mie extinction,

$$
\mathrm{N}_{\mathrm{w}}=1.5\left(\frac{\mathrm{w}}{\mathrm{m}_{\mathrm{w}, \mathrm{i}}}\right)\left[\left(\varepsilon_{\mathrm{w}, \mathrm{i}}-1\right)\left(\varepsilon_{\mathrm{w}, \mathrm{i}}+2\right)^{-1}\right]
$$

Here $m_{w, i}$ is specific weight of water droplets or ice $\left(\mathrm{g} / \mathrm{cm}^{3}\right) ; \varepsilon_{\mathrm{w}, \mathrm{i}}$ is permitivity of water or ice; $\mathrm{w}$ is water mass density $\left(\mathrm{g} / \mathrm{m}^{3}\right)$. According to Liebe, water droplets in the atmosphere form when the relative humidity exceeds saturation $(u=100-$ $101 \%$ ), whereby temperature can be as low as $-40^{\circ} \mathrm{C}$ (supercooled water). This condition has been used for enabling the cloud module in the MPM absorption model.

From all the above equations (3-7), the MPM model for non-cloudy conditions can be made up by $\mathrm{N}=\mathrm{N}_{\mathrm{D}}+\mathrm{N}_{\mathrm{V}}$ and for fog/cloud cases by $\mathrm{N}=\mathrm{N}_{\mathrm{D}}+$ $\mathrm{N}_{\mathrm{V}}+\mathrm{N}_{\mathrm{W}}$. The imaginary part of this refractivity is used for the calculation of loss of radiation energy (absorption) using equation (4). The more detailed description of the model can be found in Liebe et al. (1993).

The daily radiosonde (RS) data launched at different meteorological stations around the world are available to public users, provided by the University of Wyoming (http://weather.uwyo.edu/ upperair/sounding.html). In the present study, the daily radiosonde data for the year 2011 over two tropical stations, Mumbai $\left(72^{\circ} 49^{\prime} \mathrm{E}, 18^{\circ} 57^{\prime} \mathrm{N}\right)$ and Delhi $\left(77^{\circ} 12^{\prime} \mathrm{E}, 28^{\circ} 39^{\prime} \mathrm{N}\right)$ were collected to compute the brightness temperatures. To evaluate the forward model, the available simultaneous measurements of radiosonde and radiometer at Mahabaleshwar $\left(73.66^{\circ} \mathrm{E}, 17.93^{\circ} \mathrm{N}\right)$ are considered. 


\section{Results and discussion}

As discussed earlier, the forward model includes the computation of $T_{B} \mathrm{~s}$ using absorption coefficient and weighting functions from the known atmospheric conditions. In this section, the simulation results of these variables and comparison between estimated $T_{B} \mathrm{~s}$ from the model and observed radiometer $T_{B}$ s are presented.

\subsection{Absorption coefficient}

The absorption coefficient can be computed using MPM and known atmospheric parameters like pressure, temperature, and humidity. Absorption coefficient variation from individual modules of MPM for 1-100 GHz frequency range at an atmospheric condition of $1013 \mathrm{hPa}$ pressure, $293 \mathrm{~K}$ temperature, $100 \%$ relative humidity and $1 \mathrm{~g} / \mathrm{m}^{3}$ liquid density is shown in figure $4(\mathrm{a})$. The water vapour

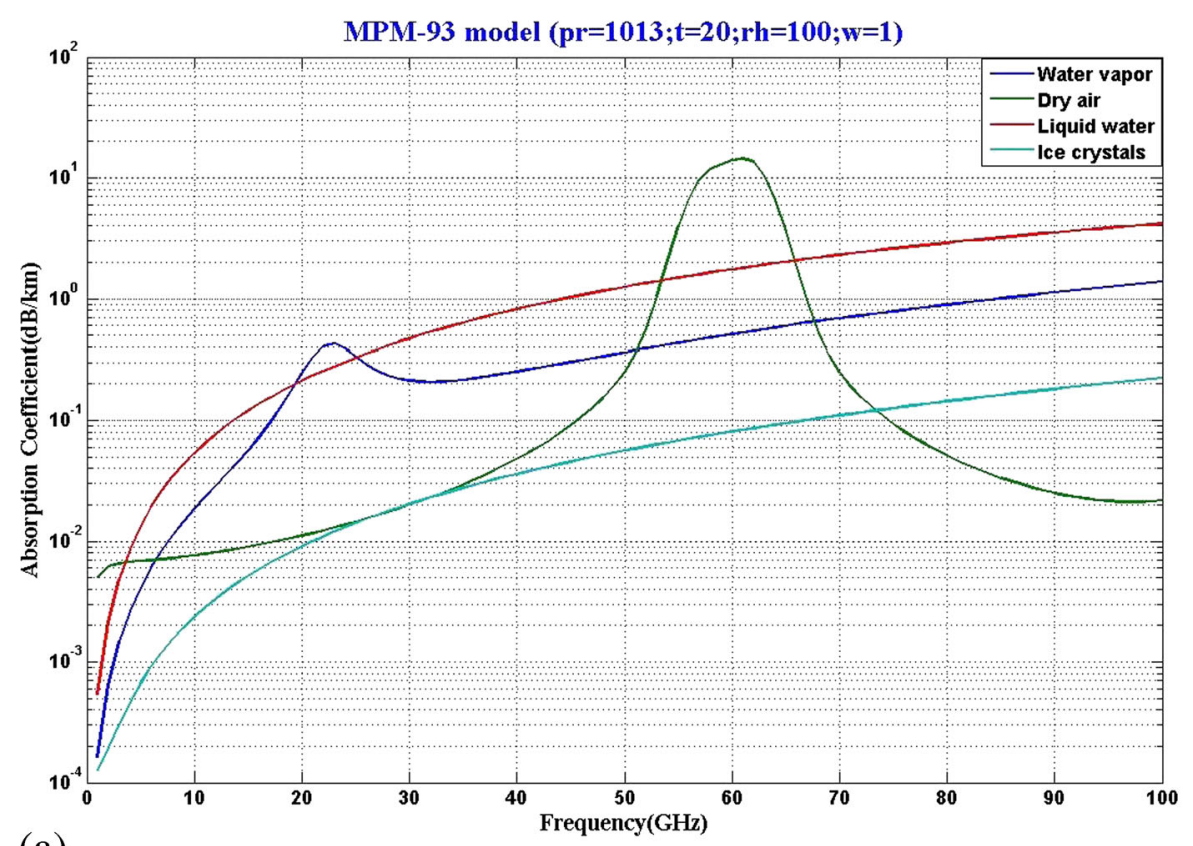

(a)

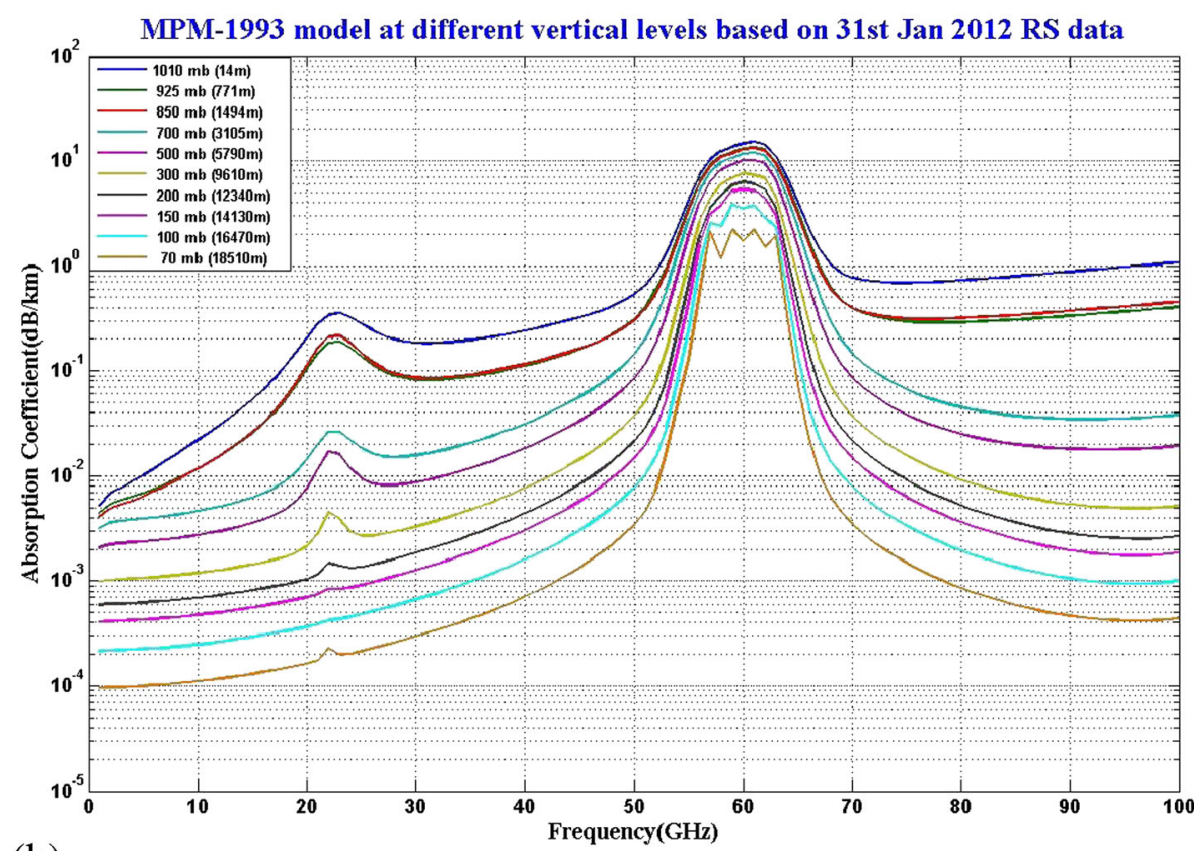

(b)

Figure 4. MPM model based absorption coefficient variation between 1 and $100 \mathrm{GHz}$ for different modules of the model (a) and the total absorption for different atmospheric levels (b). 
module shows a variation of $10^{-4}$ to $1 \mathrm{~dB} / \mathrm{km}$ with one peak rising between 20 and $28 \mathrm{GHz}$ centered at $22.235 \mathrm{GHz}$. Oxygen modules shows a peak around $60 \mathrm{GHz}$ band with absorption coefficient value of nearly $16 \mathrm{~dB} / \mathrm{km}$. Water droplet and ice crystal modules show a gradual rise of absorption with frequency. It is also observed that the absorption of liquid droplets is higher than ice crystals. Further this absorption coefficient pattern for different height levels (different atmospheric conditions) is tested using a winter day
(31 January 2012) radiosonde data (figure 4b). From this it is observed that, with increasing height, the pressure broadening absorption lines are becoming narrower. At higher heights (nearly above $16 \mathrm{~km}$ ), line structures of oxygen rotation lines can be seen, whereas at surface these lines do not appear (figure 4b). This may be due to the spectral width of each line exceeding the frequency interval between lines and hence it appearing as a continuous absorption band at the surface (Lhermitte 2002).

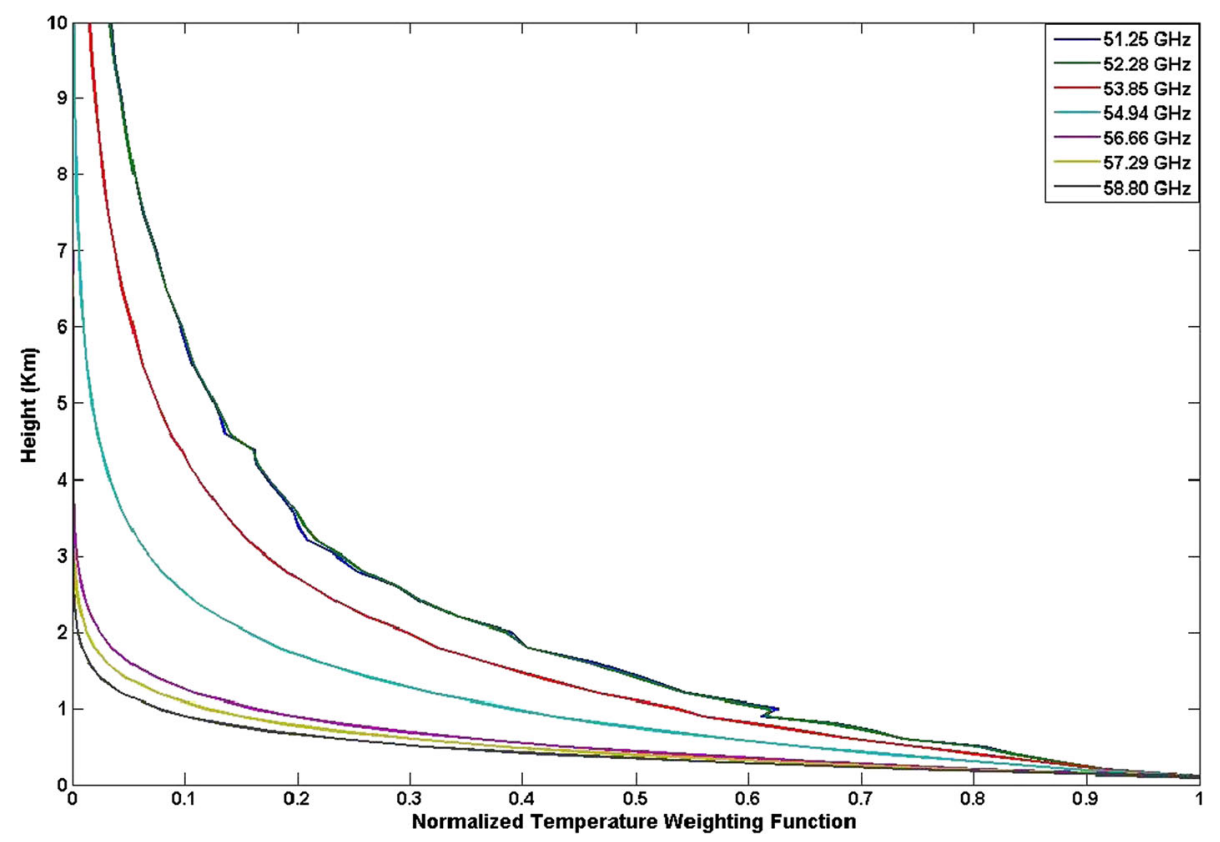

Figure 5. Normalized temperature weighting function of selected channels at 50-60 GHz broadening.

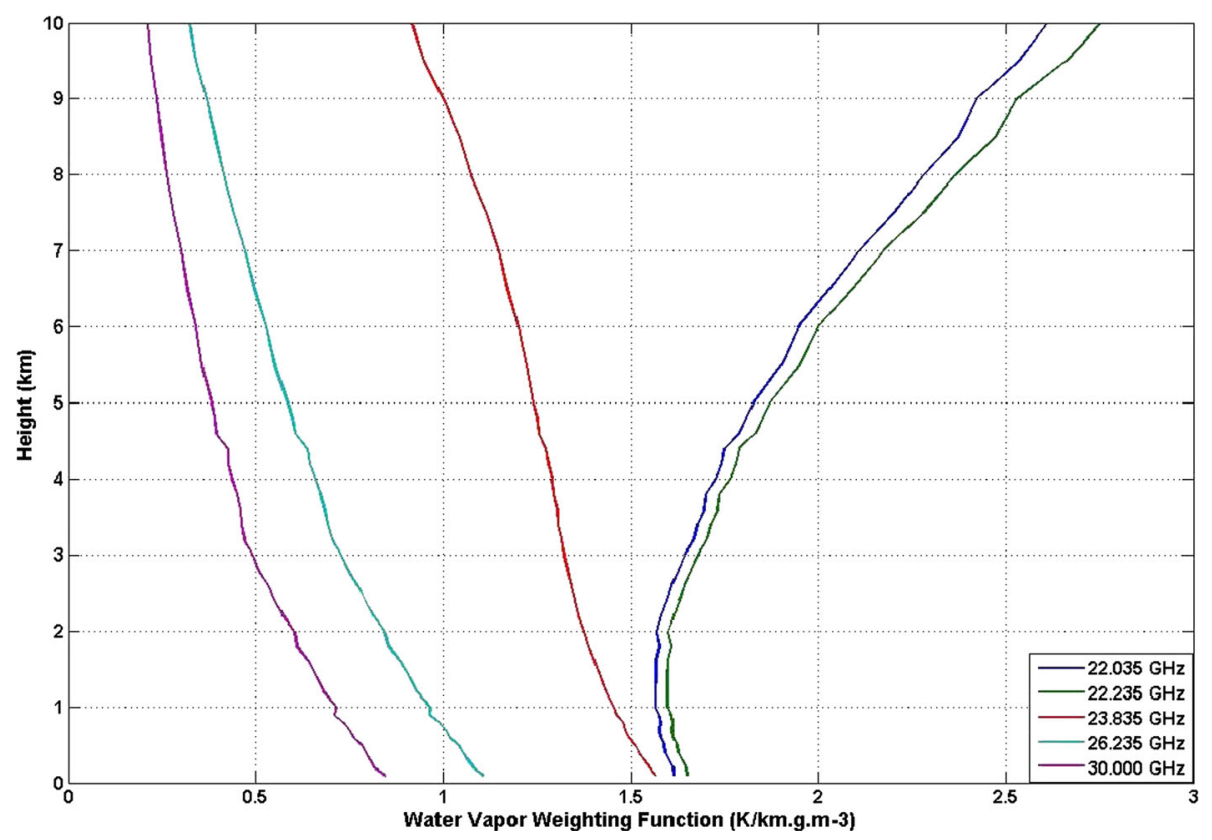

Figure 6. Water vapour weighting functions of selected channels between 20 and $30 \mathrm{GHz}$ broadening. 


\subsection{Weighting function}

The weighting function is a weightage that represents the emission contribution of each layer based on its atmospheric properties. From the absorption coefficient values, the weighting function of selected frequency channels of temperature $(50-60 \mathrm{GHz})$ and water vapour $(20-30 \mathrm{GHz})$ are analysed. The normalized (from the surface value) temperature weighting function at different frequency channels is shown in figure 5. Due to strong absorption property in the lower levels, the weighting function is large in the lower levels and gradually decreases with height. The lower frequency channels $(\sim 50 \mathrm{GHz})$ contribute nearly up to $10 \mathrm{~km}$ whereas higher frequency channels $(\sim 60 \mathrm{GHz})$ contribute below $1 \mathrm{~km}$. The weighting functions of water vapour channels have shown gradual decaying with height except in the case of $22.235 \mathrm{GHz}$, where there is a slight increase as a function of height (figure 6).

\subsection{Brightness temperature}

From the weighting functions and known temperature and humidity profiles the apparent brightness temperature can be computed (using equations 6 and 7 ). Hence to check the range of variation of $T_{B}$ values in different seasons at Mumbai and Delhi, the $T_{B}$ s of selective water vapour and temperature channels based on the RS profiles of 2011 are presented in. These profiles reveal that the range of variation is between 10 and $100 \mathrm{~K}$ for water vapour channels and 70 and $280 \mathrm{~K}$ for temperature channels.
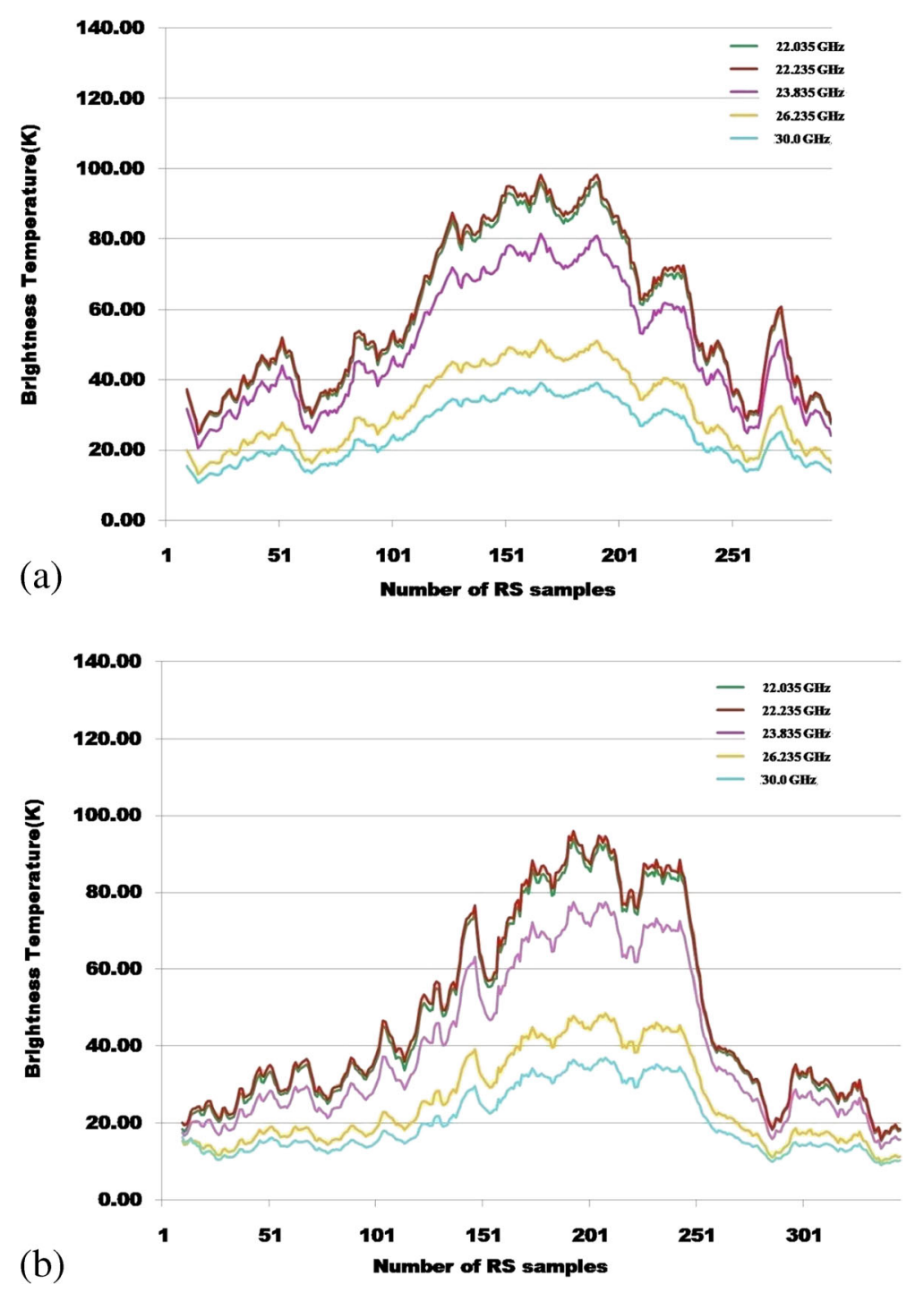

Figure 7. Forward model simulated brightness temperature of the water vapour channels for the year 2011 at (a) Mumbai and (b) Delhi. 


\subsubsection{Water vapour channels}

In the water vapour channels 22.035 and $22.235 \mathrm{GHz}$, channels have shown highest amounts of $T_{B}$ values and $30 \mathrm{GHz}$ channel has shown lowest values (figure 7). In 2011, winter months (1-50 samples) have shown the $T_{B}$ values in the range 8-59 $\mathrm{K}$ at Mumbai and $9-49 \mathrm{~K}$ at Delhi. In the pre-monsoon months there is a gradual increase of $T_{B}$ at both the stations with a range of 8-65 $\mathrm{K}$ at Mumbai and 9-59 K at Delhi. After onset of the monsoon there is a rapid increase of $T_{B}$, reaching the maximum in all the channels at both the stations. The range of $T_{B}$ is $30-99 \mathrm{~K}$ at Mumbai and 20-95 K at Delhi. During the monsoon retrieval, there is a rapid fall of $T_{B}$ at Delhi and gradual fall at coastal station Mumbai. In post-monsoon season a small peak in $T_{B}$ is observed at both the stations. On the whole, coastal station Mumbai has shown higher $T_{B}$ values than inland station Delhi.

\subsubsection{Temperature channels}

The temperature channels 51.25, 52.28, 53.85 and $54.94 \mathrm{GHz}$ have shown (figure 8) slight variation throughout the year whereas other three channels have shown decrease of $T_{B}$ in the monsoon season at both the stations. The delay of monsoon onset over Delhi compared to Mumbai is reflected in $T_{B} \mathrm{~S}$ of both temperature channels and water vapour channels.

\subsection{Evaluation of the model}

In order to evaluate the forward model, a comparison of model simulated $T_{B}$ and simultaneously measured $T_{B}$ of radiometer (MP-3000A model from Radiometrics) [Radiometrics operational manual 2008] at Mahabaleshwar station of three wet events (one event on 4 August 2011, two events on 28 June 2013) and seven dry events (1 and 19 December 2012; 2, 16 and 23 January

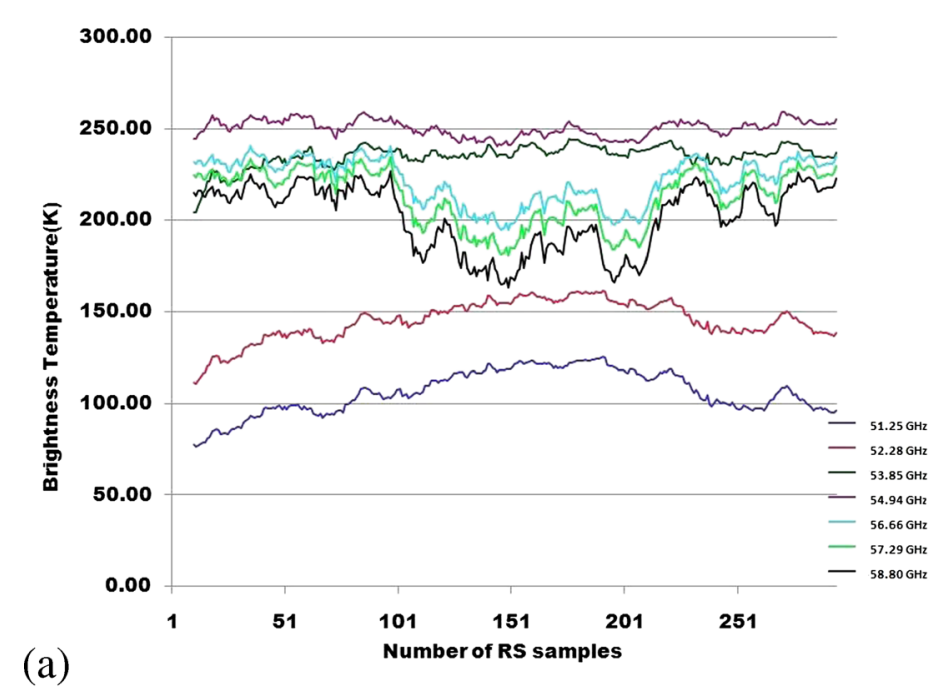

(a)

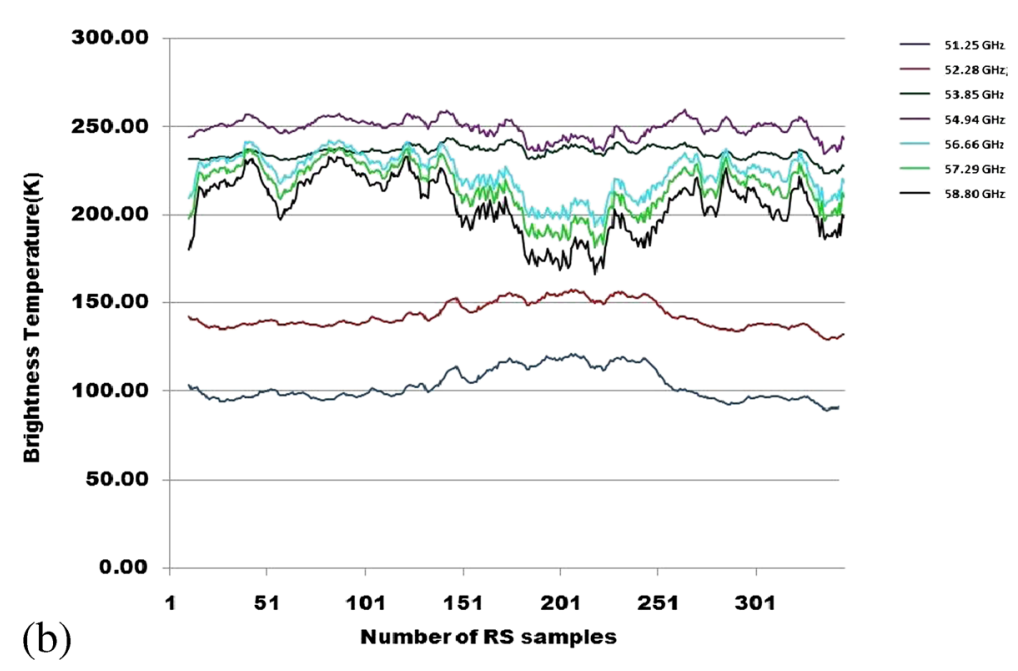

Figure 8. Forward model simulated brightness temperature of the temperature channels for the year 2011 at (a) Mumbai and (b) Delhi. 

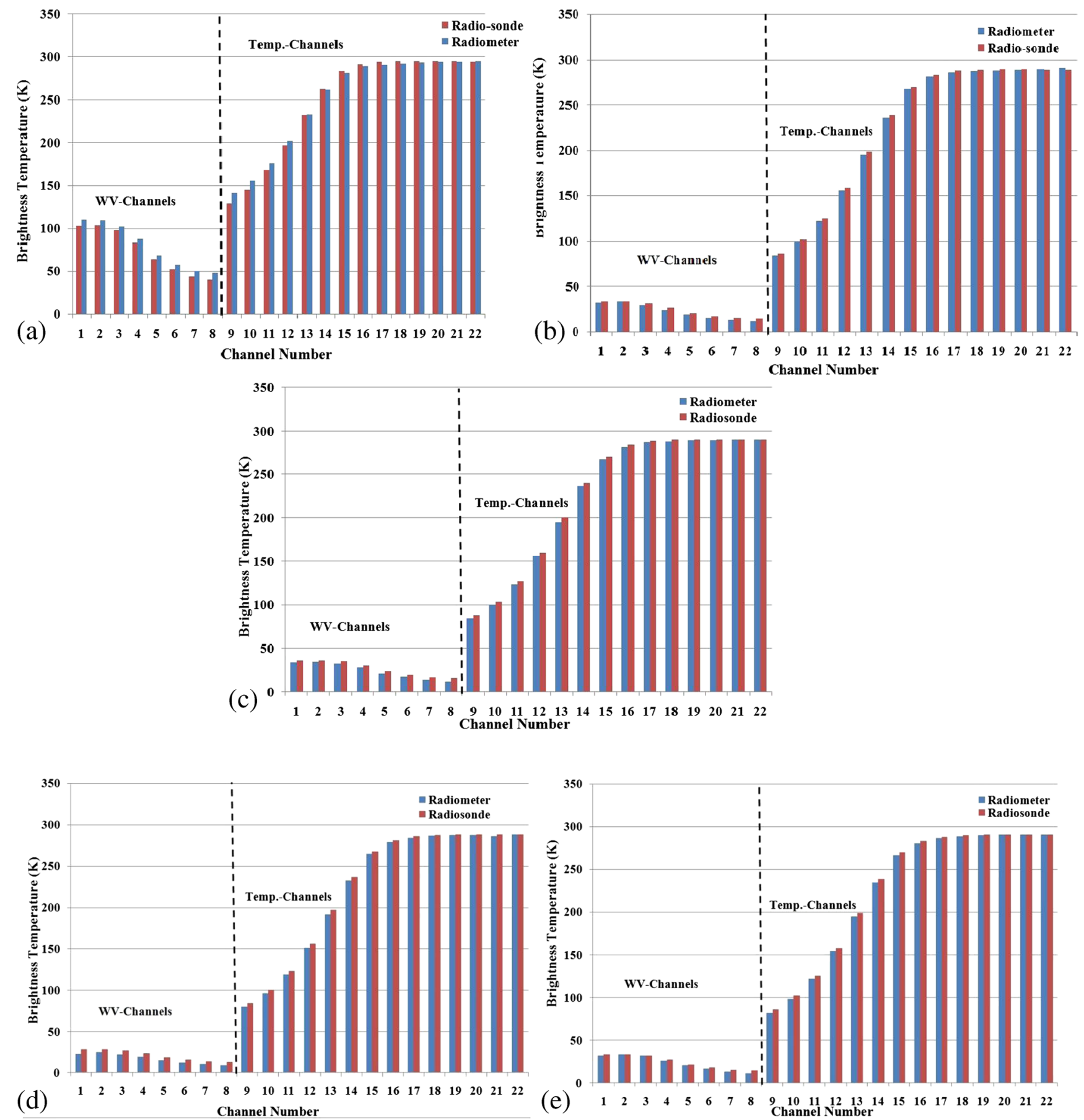

Figure 9. Comparison between model estimated and radiometer measured brightness temperature on (a) 4 August 2011, (b) 1 December 2012, (c) 2 January 2013, (d) 23 January 2013 and (e) 20 February 2013.

2013 and 6 and 20 February 2013) is shown in figures 9 and 10. The frequency channels of water vapour and temperature of this radiometer are shown in table 1 . The results show that the $T_{B}$ of water vapour channels nearly varies between 5 and $35 \mathrm{~K}$ in the dry season, whereas in the monsoon it varies between 47 and $110 \mathrm{~K}$. Similarly, the variation of $T_{B}$ of temperature channels is $77-$ $290 \mathrm{~K}$ in the dry season and that in the monsoon season is 140-293 K. Comparative analysis indicates that in most of the cases there is a good agreement between simulated and observed $T_{B} \mathrm{~S}$ of both temperature and water vapour channels with a deviation in the range of $0-5 \mathrm{~K}$. This difference in simulation and measurements may be due to the difference in the measurements of radiosonde (measures along the path of the balloon) and radiometer (measures exactly along the vertical direction). 

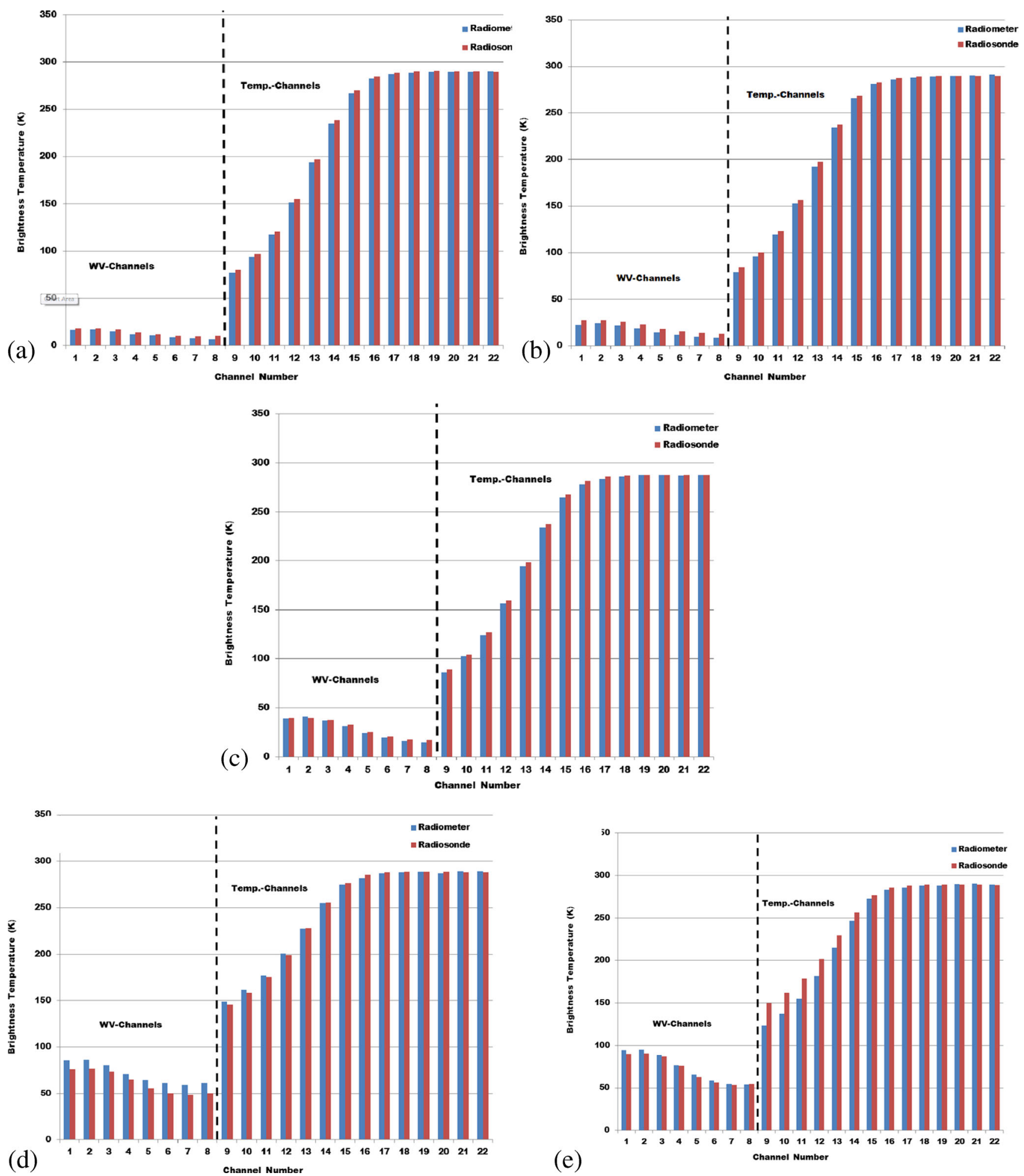

Figure 10. Comparison between model estimated and radiometer measured brightness temperature on (a) 19 December 2012, (b) 16 January 2013, (c) 6 Febuary 2013, (d) 3 GMT of 28 June 2013 and (e) 12 GMT of 28 June 2013.

However, this difference in the $T_{B}$ will be reduced through optimization of the cost function in inversion methods by adjusting the atmospheric state vector (temperature and humidity profiles).
Only on 28 June 201312 GMT (rainy time), the simulated $T_{B} \mathrm{~S}$ of some of the temperature channels have shown higher values than radiometer measures. This may be due to the erroneous 
Table 1. Frequency channels of radiometer used for evaluating the forward model.

\begin{tabular}{rcc}
\hline Sl. no. & $\begin{array}{c}\text { Water vapour } \\
\text { channel }(\mathrm{GHz})\end{array}$ & $\begin{array}{c}\text { Oxygen } \\
\text { channels }(\mathrm{GHz})\end{array}$ \\
\hline 1 & 22.234 & 51.248 \\
2 & 22.500 & 51.760 \\
3 & 23.034 & 52.280 \\
4 & 23.834 & 52.804 \\
5 & 25.000 & 53.336 \\
6 & 26.234 & 53.848 \\
7 & 28.000 & 54.400 \\
8 & 30.000 & 54.940 \\
9 & - & 55.500 \\
10 & - & 56.020 \\
11 & - & 56.660 \\
12 & - & 57.288 \\
13 & - & 57.964 \\
14 & - & 58.800 \\
\hline
\end{tabular}

measurements of radiometer and radiosonde during heavy rain time (figure 10e).

\section{Summary}

An algorithm of a forward model for a groundbased microwave radiometer is developed using radiative transfer equations and MPM based absorption model. The analysis of absorption coefficient and weighting function values in various atmospheric conditions is useful in selecting frequency channels that can be used in building the microwave radiometer. The model-simulated brightness temperature values of different seasons of 2011 over the two stations Mumbai and Delhi gave the approximate range of variation of $T_{B}$ values in different frequency channels. The difference between the date of monsoon onset over the two stations is clearly reflected in both temperature and humidity channels. As a coastal station, Mumbai is showing slightly higher values of $T_{B}$ than Delhi. Evaluation of model simulated $T_{B} \mathrm{~S}$ show good agreement with the actual measurements of microwave radiometer at Mahabaleshwar station. Simulated $\mathrm{T}_{B}$ s can be used as background information in the inversion model to retrieve the actual atmospheric state variables like temperature and humidity in continuation of this work.

\section{Acknowledgements}

The authors are grateful to authorities of Department of Electronics and Information Technology (Deity) and Society for Applied Microwave Electronics Engineering \& Research (SAMEER) for providing the facilities to carry out this work. They convey their thanks to Atmospheric Radar and Instrumentation Division (ARID) team members for their support during the work. They acknowledge the authorities of University of Wyoming website for providing radiosonde data in the public domain. Authors are thankful to anonymous reviewers, whose suggestions have resulted in substantial improvement of the paper.

\section{References}

Askne J and Westwater E 1986 A review of ground-based remote sensing of temperature and moisture by passive microwave radiometers; IEEE Trans. Geosci. Remote Sens. GE-24 340-352.

Decker M T, Westwater E R and Guiraud F O 1978 Experimental evaluation of ground-based microwave radiometric sensing of atmospheric temperature and water vapour profiles; J. Appl. Meteorol. 17 1788-1795.

Del Frate F and Schiavon G 1998 A combined natural orthogonal functions/neural network technique for the radiometric estimation of atmospheric profiles; Radio Sci. 33 405-410.

Lhermitte R M 2002 Centimeter and millimeter wavelength radars in meteorology; United States of America, AA Printing, Tampa, pp. 60-65.

Liebe H J 1987 A contribution to modeling atmospheric millimeter wave properties; Frequenz 41 31-36.

Liebe H J 1989 MPM - An atmospheric millimeter-wave propagation model; Int. J. Infrared and Millimeter Waves $10631-650$.

Liebe H J, Hufford G A and Cotton M G 1993 Propagation modeling of moist air and suspended water/ice particles at frequencies below $1000 \mathrm{GHz}$; Proc. NATO/AGARD Wave Propagation Panel, 52nd meeting, No. 3/1-10, Mallorca, Spain, 17-20 May.

Radiometrics profiler operator's manual 2008 http:// radiometrics,

Solheim F, Godwin J, Westwater E R, Han Y, Keihm S, Marsh K and Ware R 1998 Radiometric profiling of temperature, water vapour and cloud liquid water using various inversion methods; Radio Sci. 33 393-404.

Ulaby F T, Moore R K and Fung A K 1981 Microwave remote sensing: Active and passive; New York: AddisonWesley Publishing Company, Vol. 1, pp. 270-278.

Westwater E 1965 Ground-based passive probing using the microwave spectrum of oxygen; Radio Sci. 69D 12011211. 